Revista do Departamento de Geografia
Universidade de São Paulo
www.revistas.usp.br/rdg

\title{
REPRESENTAÇÕES SOCIAIS E SUA RELAÇÃO COM A QUALIDADE DE ÁGUA EM COMUNIDADES DO ENTORNO DO PARQUE ESTADUAL DO IBITIPOCA, MG-BRASIL
}

\section{SOCIAL REPRESENTATIONS AND ITS RELATIONSHIP WITH WATER QUALITY IN SURROUNDING COMMUNITIES OF THE IBITIPOCA STATE PARK, MG-BRAZIL}

\author{
Davi Fortes Galvão \\ Universidade Federal de São Carlos \\ dfortes1000@gmail.com \\ Francisco Dupas \\ Universidade Federal de Itajubá \\ Marcelo Otênio
}

Empresa Brasileira de Pesquisa Agropecuária

Recebido (Received): 04/03/2016_Aceito (Accepted): 18/07/2016

DOI: http://dx.doi.org/10.11606/rdg.v31i0.111814

Resumo: O objetivo desta pesquisa foi o de levantar a representação social (RS) das bacias hidrográficas (BHs) para as comunidades do entorno do Parque Estadual do Ibitipoca, relacionando com o estado de conservação dos recursos hídricos $(\mathrm{RH})$ e as práticas agropecuárias. Foi utilizada a técnica quali/quantitativa do discurso do sujeito coletivo (DSC) com entrevistas gravadas que recuperam opiniões, representações, posicionamentos, saberes tradicionais, crenças e atitudes. Resultou no levantamento das RS em relação aos rios e córregos relacionando-os com a qualidade dos $\mathrm{RH}$ e as variáveis de uso e cobertura do solo. Foi constatado a existência de RS mais e menos impactantes quando comparadas entre si e que essas RS afetam a qualidade dos $\mathrm{RH}$ de acordo com os discursos, analises de água e estudo do uso e cobertura do solo. Consideramos que dependendo das RS do indivíduo, existe uma maior propensão do sujeito em adotar práticas que sejam mais conservacionistas em função da RS atribuída ao tema. $\mathrm{O}$ estudo do uso e cobertura do solo mostrou como se manifestam e como as RS influenciam na utilização do solo. As análises de água foram fundamentais no relacionamento das RS com seu impacto nos $\mathrm{RH}$ das comunidades.

Palavras-chave: Discurso do sujeito coletivo; bacia hidrográfica; práticas agropecuárias.

\begin{abstract}
The objective of this research was to raise the social representations (SR) watershed (BHs) for communities surrounding the Ibitipoca State Park, relating to the conservation status of water resources (WR) and agricultural practices. Quantitative technique was used of the collective subject discourse with taped interviews that retrieve opinions, representations, placements, traditional knowledge, beliefs and attitudes. Resulted in the lifting of the $S R$ in relation to rivers and streams in relation with the quality of WR and use variables and soil cover. It was verified the existence of $S R$ more and less impactful when compared with each other and that these SR affect the quality of WR according to the speeches, analysis and study of water use and soil cover. We conclude that depending on the SR of the individual, there is a greater tendency of subject in adopting practices that are more conservationists in the SR function assigned to the theme. The study of the use and soil cover showed how manifest themselves and how the SR influence on land use. Water analyses were instrumental in the relationship of the $S R$ with its impact on WR communities.
\end{abstract}

Keywords: The collective subject discourse; the water catchment area; agricultural practices. 


\section{INTRODUÇÃOO}

A ligação entre práticas cotidianas e representações sociais (RS) tem sido de interesse para as ciências ambientais ao longo do tempo e foi particularmente estudada dentro do âmbito da teoria das RS (MOSCOVICI, 1988, 1998; ABRIC, 2001a,b). RS são definidas como modalidades de conhecimento transmitida pela sociedade e partilhada por um grupo social. Ela é uma construção social da realidade que a torna significativa e corresponde ao modo como um grupo representa mentalmente um determinado objeto (ABRIC, 2001b). Várias funções são atribuídas às RS como: gestão das relações sociais, interpretação e domínio do ambiente e justificativa de posições e comportamentos (MOSCOVICI, 1988; JODELET, 1997; ABRIC 2001b). Nesse sentido, vários autores (FLAMENT, 1987; GUIMELLI, 1998; ABRIC, 2001c) demonstraram que representações e práticas se influenciam mutuamente.

Segundo Fèlonneau (2003), é importante analisar essas RS para compreender e explicar a realidade ambiental. Elas nos ajudam a melhor entender e, às vezes, até mesmo prever, as condutas individuais e sociais em relação ao meio que envolve o grupo social. Segundo essa autora, pelo estudo das RS, podemos verificar se os sujeitos possuem representações negativas ou positivas em relação ao meio ambiente. A partir daí, podemos entender as condutas de preservação e até mesmo de agressão em relação ao meio.

Poucos estudos examinaram a associação entre as representações em relação a determinado recurso e o comportamento ambientalmente responsável. A associação entre atitude e preocupação direcionada a determinadas questões ambientais, só pode ser esperada sob certas condições, como por exemplo, a importância atribuída ao bem ambiental e a sensibilização da população (FRANSSON e GARLING, 1999).

É importante, num contex to investigativo, que se estabeleça a relação das RS com os impactos ambientais associados, a análise da qualidade dos recursos hídricos (RH) e a cobertura do uso do solo da área de estudo, pois de acordo com a presente teoria, os impactos nos RH e as diferentes dinâmicas do uso do solo estão associados com as RS de populações locais. Em um estudo realizado em Wolong, na China, LIU et al. (1999) analisaram as representações da comunidade em relação a floresta, constatando que a maioria da população avaliada tem a RS de que a floresta serve para fornecer lenha para cozinhar e aquecer. Essa coleta de lenha levou à deterioração substancial das florestas e do habitat de Ursos Pandas, ameaçados de extinção. Já no Quênia, comunidades locais tiveram a representação de que a bacia era importante para a produção e converteram florestas em terras agrícolas. O mesmo aconteceu em Altamira, no Pará, onde grande parte da Floresta Amazônica atualmente é utilizada para pastagens e agricultura (LIU et al, 2007).

Como consequência, o empobrecimento do solo tem levado a uma exploração cada vez maior de áreas florestais. Através do estudo do uso e cobertura do solo pode-se entender a dinâmica do pensamento da comunidade (RS) e seus impactos no ambiente. O entendimento dessa dinâmica é vital para a pesquisa no âmbito da sustentabilidade ambiental (LAMBIN e GEIST, 2006; LIU et al., 2007). A degradação do solo e a poluição dos RH estão intimamente ligados com as RS de populações locais.

Em Wisconsin (EUA) observou-se que a representação da comunidade estava voltada para o turismo. Isso contribuiu para o aumento e preservação de áreas florestais destinadas a visitação, atraindo turistas, e gerando desenvolvimento econômico para a região. Essa representação conduziu a práticas mais sustentáveis por parte da população local, já que vegetação conservada gera receitas econômicas para a localidade (PICHÓN, 1996; LIU et al., 2007; GRAY et al., 2008; OLDEKOP et al., 2012).

Diante do exposto, torna-se importante entender a sustentabilidade como um conceito que permeia o âmbito social, econômico e ecológico. Essas dimensões esclarecem a necessidade de compatibilizar os níveis de qualidade de vida com a preservação ambiental. Nesse enfoque, surge uma resposta à necessidade de harmonizar os processos ambientais com os socioeconômicos, maximizando a produção dos ecossistemas para favorecer as necessidades humanas presentes $\mathrm{e}$ futuras (JACOBI et al., 1998). 
Diante deste pressuposto, num sentido abrangente, JACOBI et al. (1998) e JACOBI et al. (2003), acrescentam que a noção de sustentabilidade reporta-se à necessária redefinição das relações entre sociedade humana e natureza, e, portanto, a uma mudança substancial do próprio processo civilizatório, introduzindo o desafio de pensar a passagem do conceito para a ação. A noção de sustentabilidade, por sua vez, implica também em uma necessária inter-relação entre justiça social, qualidade de vida, equilíbrio ambiental e a necessidade de um desenvolvimento, respeitando a capacidade de suporte dos ambientes (HOGAN, 1993), sejam estes construídos ou naturais. Guimarães (1997), considera a proposta de desenvolvimento sustentável plenamente justificável e legítima, sendo, entretanto, condição indispensável examinar as contradições ideológicas, sociais e institucionais do próprio discurso da sustentabilidade, bem como analisar suas distintas dimensões. No contexto brasileiro, os problemas ambientais têm se avolumado a passos gigantescos e a sua lenta resolução tem se tornado de conhecimento público pela virulência dos seus impactos.

Dessa forma, o objetivo geral desta pesquisa é levantar as RS dos membros específicos de comunidades do entorno das Bacias Hidrográficas (BHs) do Parque Estadual do Ibitipoca, MG, Brasil. Por meio dele pode-se relacionar as RS com os objetivos específicos do trabalho que são: análise da conservação/qualidade do corpo hídrico e práticas de manejo agropecuárias adotadas através do estudo do uso do solo. Essa relação foi discutida através da hipótese de que as RS dos RH por parte da comunidade influenciam na qualidade da água e a ocupação das BHs estudadas.

\section{MATERIAIS E MÉTODOS}

\section{Área de estudo}

A escolha do local de pesquisa ocorreu devido a um projeto denominado "Construção de uma Estratégia Para o Conhecimento da Bacia Hidrográfica e do Manejo dos Recursos Naturais", financiado pela Empresa Brasileira de Pesquisa Agropecuária (EMBRAPA) e pelo Conselho Nacional de Desenvolvimento Científico e Tecnológico ( $\mathrm{CNPq}$ ) e baseado no Agente Local de Desenvolvimento Comunitário (ALDC). Atuaram como monitores ambientais, jovens de dez comunidades de seis municípios, que foram treinados pela EMBRAPA e receberam uma bolsa de R \$ 100,00/mês oferecida pela Fundação de Amparo à Pesquisa do estado de Minas Gerais (FAPEMIG). Enquanto realizavam a coleta de amostras de água para análise, de 13 postos distribuídos na área de estudo do projeto, os jovens (ALDC) tornavam-se referência positiva na preservação dos córregos.

O trabalho se consolida na medida em que resulta em novas representações, discursos e práticas, que dissipam gradativamente a antiga visão, difundindo novos conhecimentos que irão transformar positivamente as práticas antes impactantes em relação aos recursos hídricos da região.

A pesquisa foi realizada em municípios do entorno do Parque Estadual do Ibitipoca, são eles: Lima Duarte, Bias Fortes, Pedro Teixeira, Ibertioga, Santana do Garambéu Santa Rita do Ibitipoca e suas 13 BHs com área total de $115,02 \mathrm{~km}^{2}$ (Figura 1).

\section{Estudo da Representação Social - Método do DSC.}

A técnica metodológica do Discurso do Sujeito Coletivo (DSC) vem sendo difundida em estudos há vários anos; trabalhos relacionados a esse tema vem sendo publicados em âmbito internacional. A exemplo disso, um estudo realizado por Storey e Oliveira (2004) utilizando-se do DSC, levantou as RS em relação a áreas preservadas de um grupo de mulheres na cidade de ManausAmazonas, Brasil, onde o objetivo foi compreender o impacto de tais RS em relação a consciência ambiental e avaliar a aplicabilidade desses dados para o planejamento de intervenções em educação ambiental (STOREY e OLIVEIRA 2004). Silva (2010) em uma publicação feita a utilizou-se do método DSC no estudo da RS da paisagem local, analisando qual a preferência desse grupo de jovens: se preferem a paisagem do ambiente urbano ou rural (SILVA, 2010). Outros estudos publicados em periódicos internacionais também foram referência na execução desse trabalho (MOSCOVICI, 1988, 1998; LIU et al., 1999; ABRIC, 2001a,b; FÈLONNEAU, 2003; STOREY e OLIVEIRA, 2004; LIU et al, 2007; SILVA 2010). 


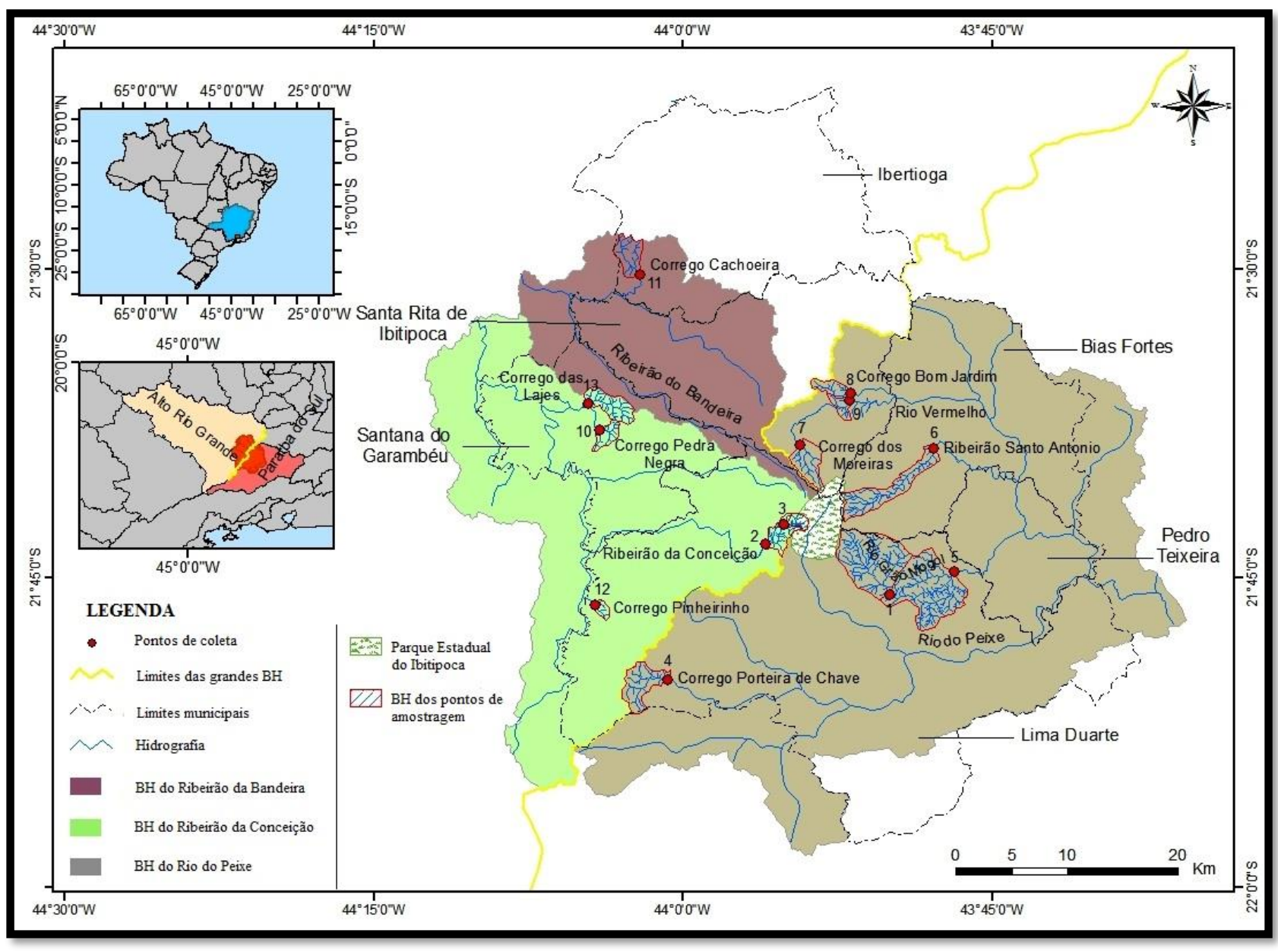

Figura 1: Localização dos municípios de Lima Duarte, Pedro Teixeira, Bias Fortes, Santa Rita do Ibitipoca, Ibertioga, Santana do Garambéu, as BHs, os pontos de amostragem e o Parque Estadual do Ibitipoca. Fonte: Elaborada pelo autor

Dentro do desenvolvimento do objetivo geral desta pesquisa, buscou-se explorar as RS dos indivíduos por meio do método do Discurso do Sujeito Coletivo (DSC) que se apresenta como uma técnica metodológica quali/quantitativa que permite o resgate de discursos coletivos. Como procedimento do método DSC as entrevistas individuais são realizadas com questões abertas, resgatando o pensamento, enquanto comportamento discursivo e fato social internalizado individualmente, podendo ser divulgado, preservando a sua característica qualitativa (LEFEVRE $e t$ $a l ., 2005$, p. 27). O DSC leva em consideração que os sujeitos interagem de acordo com o senso comum ao grupo. Cada sujeito interpreta a realidade à sua maneira, mas constrói a sua vida naquela sociedade sob influência do conhecimento consensual. O senso comum é ao mesmo tempo transformador e resistente à mudança, e esses dois aspectos paradoxais são sistemas empíricos e observáveis (MINAYO, 2007). Dessa maneira, o tamanho da amostra é representativo para a pesquisa, na medida em que leva em consideração que o que as pessoas pensam ou emitem como respostas a uma indagação reflete o compartilhamento de um imaginário social, comum, coletivo, existente num determinado momento. Dessa forma, os pensamentos contidos em expressões individuais representam mais do que um indivíduo pensa sobre um dado tema, eles revelam elementos do imaginário coletivo de um grupo (LEFEVRE e LEFEVRE, 2003). Para isso foi importante a utilização de amostras de pesquisa independentes, de diferentes perfis e de diferentes localidades sendo os atores sociais locais importantes no contexto da pesquisa.

A escolha dos sujeitos participantes na pesquisa ocorreu dentro do contexto do projeto já estabelecido em áreas do entorno do Parque Estadual do Ibitipoca onde a EMBRAPA já mantem parcerias com órgãos governamentais e com os jovens monitores dos RH. Dentro disso, os critérios de inclusão adotados para as entrevistas foram: jovens estudantes do ensino médio (JOV) membros 
do projeto, os produtores (PROD) indicados pelos jovens, os diretores das escolas (ESC) onde os jovens estudam e os técnicos da EMATER (TEC), que fazem a extensão rural nas comunidades participantes do projeto. Foram entrevistados 26 homens e 13 mulheres, na faixa etária entre 17 e 77 anos.

O questionário foi elaborado com questões que abordam as representações do meio em que vivem os entrevistados. Uma pergunta foi apresentada de maneira simples como preconiza a metodologia. A pergunta foi pré-testada antes da realização da pesquisa em campo. Ainda foi elaborada de forma que o sujeito se sinta à vontade para respondê-la podendo expressar todo seu imaginário social. É ela: No lugar onde você mora passam rios e córregos, não é mesmo? Para você, isso é importante? Por quê?

Para a construção do discurso foi utilizado o software Qualiquantsoft ${ }^{1}$ (USP, 2004). Esta ferramenta foi criada especificamente para auxiliar os trabalhos que envolvem a metodologia do DSC cuja a função é simplificar o processo de elaboração e análise dos discursos e os diferentes relacionamentos executados com dados qualitativos e quantitativos.

De acordo com a ferramenta metodológica do DSC buscou-se extrair: a) expressões chave $(\mathrm{ECH})$ que caracteriza a resposta de cada entrevistado; b) a classificação e agrupamento dessas expressões em categorias e c) a construção de um discurso coletivo para cada uma das ideias centrais (IC) da pergunta realizada. Utilizando-se da metodologia do DSC foram extraídas ECH e as IC, estas foram trabalhadas para o entendimento da RS dos rios e córregos em quatro categorias para IC, são elas: "rios e córregos importantes para produção; rios e córregos importantes para o dia a dia das pessoas; rios e córregos importantes para a dinâmica ambiental; e água é vida".

Ao método DSC buscou-se associar parâmetros físicos, químicos e biológicos da água e o respectivo uso e cobertura do solo, associando com palavra-chave e discursos das RS dos indivíduos e relacionando esses discursos com impactos negativos aos $\mathrm{RH}$ e as práticas da comunidade na $\mathrm{BH}^{2}$.

\section{Mapeamento do uso e cobertura do solo}

Utilizou-se o sensoriamento remoto para determinação dos temas de uso e cobertura do solo juntamente com o Sistema de Informação Geográfica, possibilitando correlacionar a RS da comunidade indicando seu pensamento sobre os RH e tendências a influenciar sua ocupação. Os temas extraídos foram: reflorestamento/vegetação em recuperação, vegetação recuperada, agricultura, água, pastagem e solo exposto. A determinação desses temas é realizável por meio da interpretação utilizando-se recursos apresentados na imagem tais como forma, tamanho, tom, sombra, padrões e textura (LILLESAND e KIEFER, 1994).

Para os trabalhos de mapeamentos utilizou-se o ArcGIS versão 9.3 através do qual delimitouse as BHs de cada ponto de amostragem por meio da sobreposição de cartas do Instituto Brasileiro de Geografia e Estatística (IBGE). Desse modo, as três grandes BHs do Rio do Peixe, do Rio da Bandeira e do Rio da Conceição ficaram posicionadas dentro da bacia do Alto Rio Grande e do Rio Paraíba do Sul.

\section{Monitoramento dos corpos hídricos}

Para realização das diferentes análises da água de córregos e rios os agentes ambientais, utilizaram o Ecokits, o kit Cardkit e o Tecnobac, conforme a metodologia descrita por Hermes e Silva (2004). Essas ferramentas permitiram aos jovens do ensino médio, treinados pela Embrapa Gado de Leite, monitorar a qualidade da água nas localidades onde residem, determinando diversas variáveis

\footnotetext{
1 Universidade de São Paulo. Software qualiquantsoft, Licenciado por USP, Universidade de São Paulo. 2004. SOFTWARE QUALIQUANTISOFT. Disponível em: 〈www.spi-net.com.br〉

${ }^{2}$ Este trabalho foi submetido e aprovado via Plataforma Brasil pelo Comitê de Ética em Pesquisa da Universidade Federal de Juiz de Fora-MG, tendo um número de protocolo de 107.406 datado de 5/11/2012
} 
físico-químicas e microbiológicas da água (Tabelas 2 e 3). Esses jovens receberam além de treinamento, uma bolsa de 100 reais como contrapartida as análises realizadas.

Foram analisadas amostras a cada 15 dias em um período de tempo de 10 meses (estação seca e chuvosa), sendo consideradas as médias dos parâmetros dos meses referentes ao período de estiagem com as médias dos parâmetros dos meses referentes ao período da estação chuvosa. Os valores obtidos para cada parâmetro analisado nas diferentes BHs foram comparados com os valores de referência presentes na seção que dispõe sobre as diretrizes ambientais para o seu enquadramento da legislação CONAMA 357/2005. Na Figura 2 tem-se um resumo da estrutura conceitual e metodológica que orientou a redação do manuscrito. Este quadro foi relacionado com os objetivos e resultados esperados do trabalho.

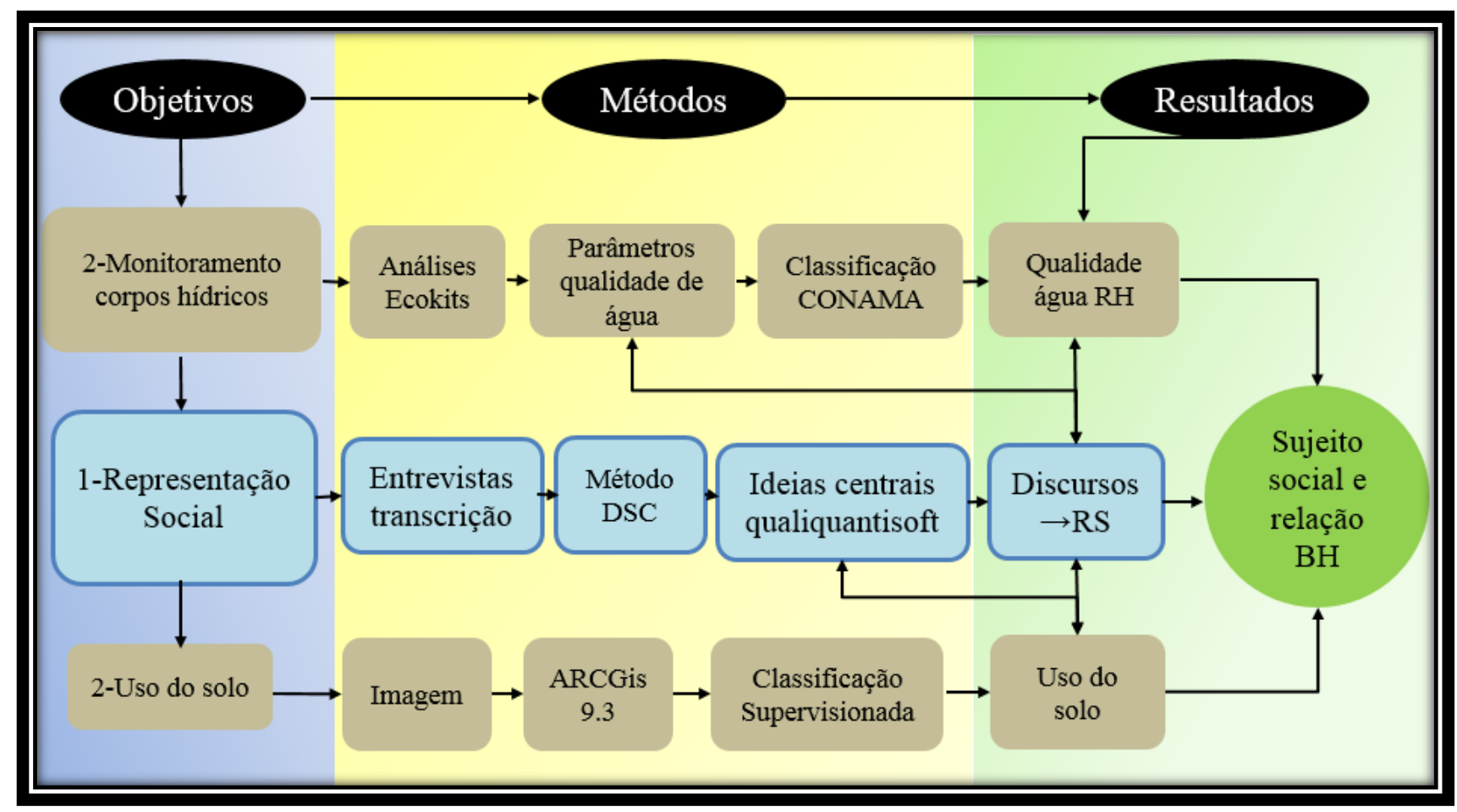

Figura 2: Esquema sistematizando o fluxo das informações trabalhadas e obtidas por meio dos métodos utilizados. Fonte: Elaborada pelo autor

\section{RESULTADOS E DISCUSSÕES}

\section{Uso cobertura do solo e parâmetros específicos de análise da água}

A Tabela 1 apresenta a média em percentual das áreas separadas por classes de uso e ocupação realizado através do trabalho de geoprocessamento. Quando analisadas as coberturas das $13 \mathrm{BHs}$ pode-se observar que o uso do solo está voltado principalmente para a produção de gado de corte, produção de leite com pastagens extensivas e também a agricultura sazonal, denotando características socioambientais apresentando elevados impactos principalmente pela produção agropecuária (Figura 3). A predominância de pastagens resulta em uma fragilidade ambiental acentuada. Essa utilização econômica do solo mantém laços de retroalimentação com as RS colaborando para a manutenção da situação. Dessa maneira, o solo tende a ficar mais suscetível a escorregamentos, baixa variabilidade de fauna e flora, assoreamento e baixa retenção hídrica, ocasionando o carreamento de elementos químicos/físicos nocivos as BHs da região, prejudicando as atividades, usos e representações das populações que mantem suas vidas girando em torno desses rios. O estudo do uso do solo por meio das RS evidencia a dinâmica da relação que se estabelece entre ambos, conforme pode-se observar na Tabela 1. 
Tabela 1: Média Percentual de Uso do Solo nas 13 BHs

\begin{tabular}{|c|c|}
\hline Classes de uso do solo & Áreas (\%) - média de uso das 13 BHs \\
\hline Pastagem & 44,9 \\
\hline Agricultura & 19,1 \\
\hline Reflorestamento e/ou vegetação em recuperação & 14,8 \\
\hline Solo exposto & 9,6 \\
\hline Vegetação regenerada & 11,6 \\
\hline
\end{tabular}

Fonte: Elaborada pelo autor

Em relação as análises de água, as Tabelas 2 e 3 apresentam os valores médios de cada parâmetro analisado para os períodos de seca (Tabela 2) e de chuva (Tabela 3) nos diferentes pontos de amostragem nas diferentes BHs. De um modo geral, a maioria dos parâmetros se enquadrou dentro do limite do CONAMA 357 para águas da Classe 2. Os pontos 5, 6 e 9 apresentaram valores de coliformes fecais acima do valor máximo permitido (VMP) de $1000 \mathrm{NMP} / 100 \mathrm{~mL}$ na estação chuvosa e o ponto 9 na estação seca. Já os coliformes totais estão presentes em todos os corpos de água em quantidades consideráveis, o que evidencia a vocação econômica da região (Figura 3), levantando discussões de investimentos em saneamento básico, praticas agropecuária, educação ambiental, desenvolvimento tecnológico, conservação ambiental visando atender essas populações. No ponto 9 , no rio Vermelho, os coliformes fecais podem ser provenientes também de um tributário próximo que recebe efluentes de um pequeno laticínio.

Tabela 2: Dados físico-químicos da água, valores médios para o período de seca, nos 13 pontos de amostragem nas diferentes BHs em estudo. Valor máximo Permitido (VMP)

\begin{tabular}{|c|c|c|c|c|c|c|c|c|c|c|c|c|c|c|}
\hline \multicolumn{15}{|c|}{ CAMPANHA DE SECA } \\
\hline $\begin{array}{l}\text { Parâmetros } \\
\text { /Ponto }\end{array}$ & 1 & 2 & 3 & 4 & 5 & 6 & 7 & 8 & 9 & 10 & 11 & 12 & 13 & $\begin{array}{c}\text { VMP } \\
\text { Classe 2 }\end{array}$ \\
\hline $\begin{array}{c}\text { Colif. fecal/termot. } \\
\text { (UFC/100mL) }\end{array}$ & 558,7 & 435 & 424 & 150,5 & 496,7 & 930 & 557 & 465 & $\underline{1098}$ & 490 & 830 & 550 & 320 & $\underline{1000}$ \\
\hline $\begin{array}{c}\text { Coliforme total } \\
\text { (UFC/100mL) }\end{array}$ & 1110 & 1545 & $\begin{array}{c}211 \\
5 \\
\end{array}$ & 1875 & 870 & 1700 & 1575 & 1215 & 1465 & 623 & 940 & 855 & 1200 & \\
\hline $\begin{array}{c}\text { Salmonella } \\
\text { (UFC/100mL) }\end{array}$ & 0 & 255 & 80 & 160 & 150 & 120 & 60 & 0 & 445 & 60 & 90 & 0 & 30 & \\
\hline $\begin{array}{c}\text { Oxigênio } \\
\text { Dissolvido }\left(\mathrm{mg} \mathrm{L}^{-1}\right. \\
\left.\mathrm{O}_{2}\right) \\
\end{array}$ & 6,3 & 6,12 & 9,1 & 7,6 & 5,42 & 7,6 & 8,37 & 8,05 & 8,2 & 8,9 & 8,9 & 5,71 & 7,60 & $\geq 5$ \\
\hline $\begin{array}{l}\text { Cloreto }\left(\mathrm{mg} \mathrm{L}^{-1}\right. \\
\mathrm{Cl})\end{array}$ & 29,3 & 30 & 25 & 52,5 & 31,2 & 22 & 17,1 & 21,4 & 25,7 & 40,0 & 26,5 & 20,5 & 21 & $\underline{250}$ \\
\hline $\mathrm{pH}$ & 6 & 6,3 & 6,2 & 5,9 & 6 & 6,5 & 7 & 7 & 6,5 & 6,5 & 7 & 7 & 6,2 & $\underline{6 \text { a } 9}$ \\
\hline Turbidez (NTU) & 50 & 45 & 45 & 56 & 50 & 50 & 100 & 50 & 50 & 50 & 50 & 56 & 50 & $\underline{100}$ \\
\hline $\begin{array}{c}\text { Nitrogênio } \\
\text { amoniacal } \\
\left(\mathrm{mg} \mathrm{L}^{-1} \mathrm{~N}-\mathrm{NH}_{3}\right) \\
\end{array}$ & 0,81 & 0,89 & 1,09 & 0,15 & 1,32 & 0,57 & 0,56 & 0,2 & 0,63 & 0,15 & 0,09 & 1,10 & 0,15 & $\underline{3,7}$ \\
\hline Ferro $\left(\mathrm{mg} \mathrm{L}^{-1} \mathrm{Fe}_{2}\right)$ & 0,29 & 0,28 & 0,25 & 0,25 & $\underline{0,38}$ & 0,25 & 0,25 & 0,25 & 0,25 & 0,25 & 0,25 & $\underline{0,46}$ & 0,25 & $\underline{0,3}$ \\
\hline $\begin{array}{l}\text { Ortofosfato } \\
\left(\mathrm{mg} \mathrm{L}^{-1} \mathrm{PO}_{4}\right)\end{array}$ & 0,01 & 0,11 & 0,14 & 0,03 & 0,33 & 0,17 & 0,18 & 0,08 & 0,22 & 0,18 & 0,04 & 0,34 & 0,12 & \\
\hline $\begin{array}{c}\text { Nitrato } \\
\left(\mathrm{mg} \mathrm{L}^{-1} \mathrm{~N}-\mathrm{NO}_{3}\right) \\
\end{array}$ & 1,34 & 1,83 & 1,50 & 0,66 & 0,45 & 0,82 & 1,58 & 0,77 & 1,33 & 1,33 & 0,44 & 1,66 & 0,66 & $\underline{10}$ \\
\hline $\begin{array}{c}\text { Nitrito } \\
\left(\mathrm{mgL}^{-1} \mathrm{~N}-\mathrm{NO}_{2}\right)\end{array}$ & 0,08 & 0,07 & 0,12 & 0,16 & 0,09 & 0,03 & 0,03 & 0,03 & 0,03 & 0,03 & 0,03 & 0,70 & 0,22 & $\underline{1}$ \\
\hline
\end{tabular}

Fonte: Elaborada pelo autor. Legenda: os seguintes valores dos parâmetros que ultrapassaram o VMP para cada BH (destaque em vermelho grifado na tabela) estão identificados abaixo: BHs 5 e 12: ultrapassaram o VMP para Ferro. Valores: 038/0,46 mg L $\mathrm{L}^{-1}$ respetivamente; $\mathrm{BH}$ 9: ultrapassou o VMP para Coliforme fecal termotolerante. Valor: $1098 \mathrm{UFC} / 100 \mathrm{~mL}$ 
Tabela 3: Dados físico-químicos da água, valores médios para o período chuvoso, nos 13 pontos de amostragem nas diferentes BHs em estudo.

\begin{tabular}{|c|c|c|c|c|c|c|c|c|c|c|c|c|c|c|}
\hline \multicolumn{15}{|c|}{ CAMPANHA DE CHUVA } \\
\hline $\begin{array}{l}\text { Parâmetros } \\
\text { /Ponto }\end{array}$ & 1 & 2 & 3 & 4 & 5 & 6 & 7 & 8 & 9 & 10 & 11 & 12 & 13 & $\begin{array}{c}\text { VMP } \\
\text { Classe 2 }\end{array}$ \\
\hline $\begin{array}{l}\text { Colif. fecal/termot. } \\
\text { UFC/100mL }\end{array}$ & 744 & 379,8 & 410 & 312 & $\underline{1130}$ & $\underline{1065}$ & 552 & 680 & $\underline{1120}$ & 600 & 465 & 900 & 870 & $\underline{1000}$ \\
\hline $\begin{array}{l}\text { Coliforme total } \\
\text { UFC/100mL }\end{array}$ & 1370 & 53760 & 48735 & 1008 & 1249 & 17220 & 1560 & 3200 & 4500 & 2130 & 5187 & 1008 & 2232 & \\
\hline $\begin{array}{l}\text { Salmonella } \\
\text { UFC/100mL }\end{array}$ & 0 & 0 & 0 & 120 & 120 & 60 & 343 & 0 & 0 & 0 & 0 & 120 & 0 & \\
\hline $\begin{array}{l}\text { Oxigênio } \\
\text { Dissolvido } \\
\left(\mathrm{mg} \mathrm{L}^{-1} \mathrm{O}_{2}\right)\end{array}$ & 7,14 & 7,95 & 7,43 & 5,64 & 6,48 & 5,02 & 6,8 & 8,3 & 7,55 & 8,71 & 9,80 & 5,64 & 8,9 & $\geq \underline{5}$ \\
\hline $\begin{array}{c}\text { Cloreto } \\
\left(\mathrm{mg} \mathrm{L}^{-1} \mathrm{Cl}\right)\end{array}$ & 54,66 & 39,25 & 36,43 & 24,00 & 43,60 & 36,20 & 82,00 & 22,34 & 46,66 & 37,00 & 74,02 & 24,00 & 40 & $\underline{250}$ \\
\hline $\mathrm{pH}$ & 5,7 & 6,0 & 6,5 & 6,2 & 5,8 & 6,9 & 7,3 & 6,3 & 6,6 & 6,3 & 6,5 & 6,2 & 6,2 & $\underline{6 \text { a } 9}$ \\
\hline Turbidez (NTU) & 59,1 & 50 & 50 & 50 & 50 & 50 & 100 & 55,5 & 60 & 50 & 78,5 & 50 & 50 & $\underline{100}$ \\
\hline $\begin{array}{c}\text { Nitrogênio } \\
\text { amoniacal }\left(\mathrm{mg} \mathrm{L}^{-1}\right. \\
\left.\mathrm{N}-\mathrm{NH}_{3}\right) \\
\end{array}$ & 0,54 & 1,11 & 1,57 & 0,12 & 0,81 & 0,81 & 0,94 & 0,12 & 0,18 & 1,16 & 0,18 & 0,13 & 0,12 & $\underline{3,7}$ \\
\hline Ferro $\left(\mathrm{mg} \mathrm{L}^{-1} \mathrm{Fe}_{2}\right)$ & 0,08 & 0,31 & 0,25 & 0,13 & 0,67 & 0,42 & 2,16 & 0,11 & 0,16 & 0,22 & 0,02 & 0,13 & 0,25 & $\underline{0,3}$ \\
\hline $\begin{array}{l}\text { Ortofosfato } \\
\left(\mathrm{mg} \mathrm{L}^{-1} \mathrm{PO}_{4}\right)\end{array}$ & 0,05 & 0,11 & 0,17 & 0,03 & 0,38 & 0,18 & 0,24 & 0,05 & 0,14 & 0,40 & 0,04 & 0,02 & 0,04 & \\
\hline $\begin{array}{c}\text { Nitrato } \\
\left(\mathrm{mg} \mathrm{L}^{-1} \mathrm{~N}-\mathrm{NO}_{3}\right)\end{array}$ & 0,48 & 0,44 & 0,47 & 0,44 & 0,44 & 0,61 & 0,22 & 0,24 & 0,49 & 0,47 & 0,19 & 0,44 & 0,44 & $\underline{10}$ \\
\hline $\begin{array}{c}\text { Nitrito } \\
\left(\mathrm{mgL}^{-1} \mathrm{~N}-\mathrm{NO}_{2}\right)\end{array}$ & 0,02 & 0,03 & 0,04 & 0,03 & 0,03 & 0,05 & 0,04 & 0,03 & 0,06 & 0,04 & 0,00 & 0,03 & 0,03 & $\underline{1}$ \\
\hline
\end{tabular}

Fonte: Elaborada pelo autor. Legenda: os seguintes valores dos parâmetros que ultrapassaram o VMP para cada BH (destacados em vermelho grifado na tabela) estão identificados abaixo: BH 2,5,6,7 ultrapassaram o VMP para Ferro. Valores:0,31 /0,67/ 0,42/ 2,16 mg $\mathrm{L}^{-/}$respectivamente; BHs 5, 6, 9: ultrapassaram o VMP para Coliforme fecal termotolerante. Valores: 1130/ 1065/ 1120 UFC/100mL respectivamente

O ferro foi outra variável que apresentou valores acima do VMP (valor máximo permitido) em alguns pontos de amostragem principalmente na estação chuvosa. $O$ nível de ferro aumenta nas estações chuvosas devido ao carreamento de solos e a ocorrência de processos de erosão das margens, o que evidencia a falta de uma cobertura vegetal adequada que minimize certos impactos do solo e consequentemente na água. Apesar de estudos não comprovarem problemas de saúde graves com a presença do ferro na água nos humanos, para os bovinos a situação pode ser diferente. De acordo com Boyne e Arthur (1986) o excesso de ferro aumenta o risco de infecção e neoplasia e promove insuficiência secundária de cobre comprometendo a primeira linha de respostas de defesa imunológica dos animais.

A maioria dos pontos de coleta apresenta $\mathrm{pH}$ com tendência à ácido, característica das águas brasileiras pelo tipo de solos que escoam. A turbidez também apresentou valores elevados em quase todas as amostras e apesar de, na maioria das análises, não ultrapassar os VMP para a classe 2, esses valores podem estar relacionados com o uso e cobertura do solo, as atividades agropecuárias, a lixiviação e também as representações e práticas associadas a elas em relação aos RH da região. As concentrações de oxigênio dissolvido foram adequadas em todos os pontos amostrados, o que indica uma boa circulação e autodepuração do sistema.

As bactérias do grupo coliforme são definidas na Portaria $n^{\circ}$ 2.914/2011 do Ministério da Saúde como: coliformes totais, sendo representadas por bacilos gram-negativos do gênero Esherichia e coliformes termotolerantes, sendo representadas pela Escherichia coli, de origem exclusivamente fecal. Dessa forma, os coliformes termotolerantes são encontrados em todas as análises dos córregos verificados, mesmo que não ultrapassando o VMP estipulado pela resolução CONAMA 357 para a classe 2. Esse indicador é importante quando relacionamos com os discursos das RS dos entrevistados. Algumas das RS levantadas estão ligadas a atividades econômicas da região, como a pecuária e agricultura e também ao uso da água no dia a dia, atrelando a esse uso o descarte do esgoto sanitário de muitas residências da área de estudo e também atividades domésticas. Outros agentes 
químicos importantes, ligados a atividades agrícolas também foram encontrados: nitrito, nitrato, nitrogênio dentre outros, evidenciando uma íntima relação entre as RS e os RH.

As bactérias do tipo Salmonellas também foram encontradas em mais da metade das amostras, sendo que em 9 das 15 amostras em que elas estiveram presentes o valor foi acima de 100 UFC/ML. Essas bactérias estão associadas a ocorrência de diversas doenças locais como gastroenterite, septicémia, febre entérica, dentre outras, que acometem a população em contato com a água. Diante disso, os riscos para a população mostram-se preocupantes, uma vez que os hospitais estão distantes das áreas rurais da região.

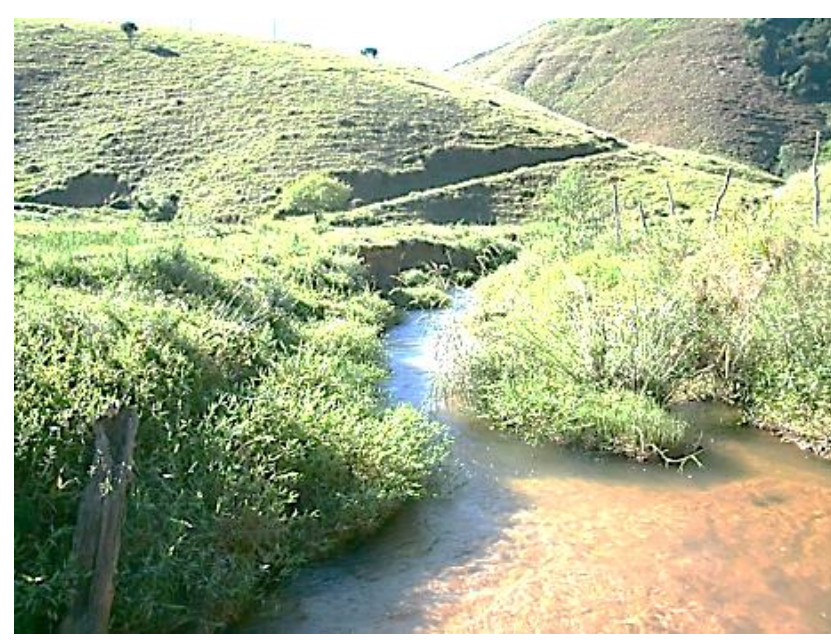

Pt.1 - Rio Grão Mogol, município de Lima Duarte

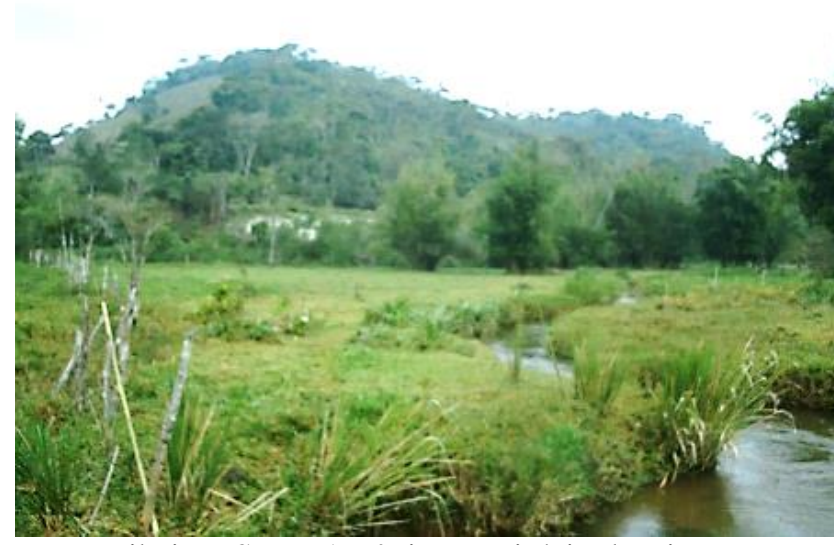

Pt. 6- Ribeirão Santo Antônio, município de Bias Fortes.

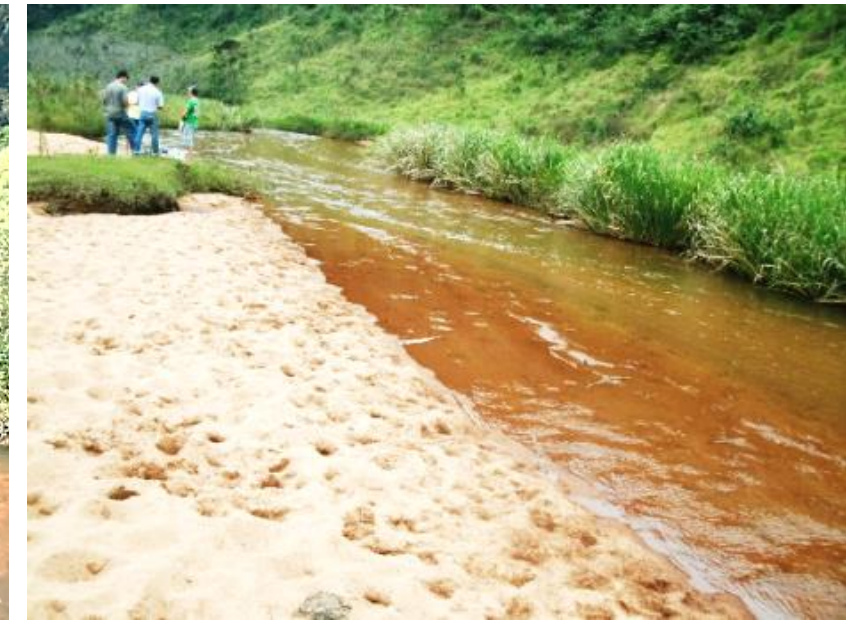

Pt. 5 Rio Grão Mogol, Lima Duarte

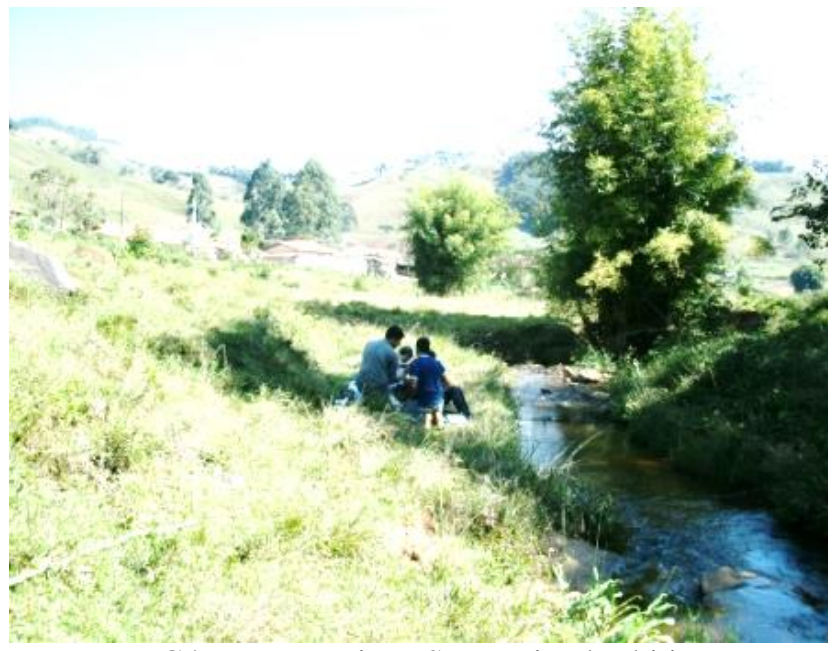

Pt. 7- Córrego Moreiras, Santa Rita do Ibitipoca

Figura 3: Fotografias de alguns pontos de amostragens apresentando a cobertura vegetal do entorno dos rios analisados conduzindo-nos a fazer reflexões sobre a vocação econômica da região e os impactos ambientais associados. Fonte: autor

\section{A Representação Social dos Rios e Córregos}

Em conjunto com o estudo de uso e cobertura do solo e de análise de água das BHs onde vivem as pessoas da área objeto de estudo, buscou-se relacionar a esses dados o estudo das RS dos rios e córregos para uma visão sistematizada dos fatores que influenciam a qualidade de água dos RH da região. PERGUNTA 1: No lugar onde você mora passam rios e córregos, não é mesmo? Para você, isso é importante? Por quê? 


\section{Rios e córregos são importantes para produção}

Ao observar algumas das IC extraídas das Ech das respostas dos membros das comunidades, foi possível detectar padrões nos seus sentimentos em relação à representação dos rios e córregos. A frase "sem água não se produz", por exemplo, apresenta aspectos de utilidade pessoal, ou seja, água para eles representa isso; com a água ele produz e com a produção ele vai usufruir de outros benefícios, como a aquisição de bens de consumo. Para essas pessoas a água representa além de tudo, seu sustento, deixando para segundo plano a utilização da água para beber, lavar e outros usos comuns a todos.

A pergunta 1 teve 30,0\% de ICs que consideraram que os rios e córregos são importantes para a atividade de produção. Essas atividades e essa RS voltada para a produção impacta a qualidade de água dos rios que passam pelas comunidades estudadas.

Trechos do discurso da comunidade com IC de que os rios e córregos são importantes para a produção apoiam a afirmativa de que o modo como a comunidade observa a utilidade daquele corpo hídrico impacta na qualidade ambiental desse recurso com práticas não adequadas como mostra esse trecho do discurso: "porque lá cria gado e sem água não teria jeito, e também planta muita coisa e irriga estas plantas; é bom para a planta, sem água as plantas não produzem. Para tudo o rio é importante, tem importância fundamental para irrigação. É bom ter água por perto. Assim a água vai estimular a agricultura, pecuária, sem água os animais não produzem”. Assim de acordo com os discursos dessa respectiva representação pode-se inferir o potencial impactante dessas atividades nos $\mathrm{RH}$.

Observou-se em todos os pontos analisados a presença de coliformes para as médias sazonais acima de 200UFC/100ml. Os resultados para as estações secas e chuvosas demonstram que em apenas 1 bacia não foi encontrado ortofosfatos em quantidades significativas (Tabelas 2 e 3). Em relação ao nitrogênio amoniacal, foram encontrados valores significativos para este elemento em todos os pontos avaliados. A utilização desses elementos é relacionada com a utilização de fertilizantes artificiais.

Os elementos prejudiciais a qualidade da água encontrados que são associados a produção e ao uso do solo das BHs evidencia que essa RS, que é voltada para produção, tende a impactar de forma mais evidente e instantânea os RH que passam próximos a sua comunidade.

Dentre as principais fontes poluidoras: indústrias, residências e a agricultura, Guillou e Moser (2006) afirmam que a atividade produtiva agrícola tem um potencial poluidor muito grande e os agricultores não reconhecem sua atividade como sendo de grande contribuição à poluição dos rios, atribuindo isto à indústria e às residências. Se o produtor não observar o que ele faz, como danoso ao meio ambiente, dificilmente mudará sua mentalidade. Assim, ele não adotará práticas ambientais menos poluidoras em relação aos rios, demandando um trabalho intensivo no âmbito da educação ambiental.

\section{Rios e córregos são importantes no dia a dia das pessoas}

Do total de respostas, 17 ICs foram utilizadas na construção do DSC de que os rios e córregos são importantes no dia a dia das pessoas. Ao utilizar as ICs extraídas das ECH das respostas dos membros da comunidade, foi possível perceber que os entrevistados têm interesse em suas atividades diárias. Muitos relataram em suas respostas que os rios são importantes para jogar os dejetos, afirmando: "para onde vai a descarga se não para os rios"? evidenciando impactos negativos associados a essa RS.

Na pergunta 1, $34 \%$ das ICs consideraram os rios e córregos importantes para o dia a dia das pessoas. Dentro do DSC dessa IC podemos destacar trechos como: "Eu preciso dos rios para pegar água para gente usa no dia a dia, a gente precisa de água pra nós lava roupa, pra nós faze a comida, lava as vasilhas. Serve para carregar os dejetos dessas pessoas; aquilo que vem do banheiro joga no rio". Nesse trecho do DSC o rio se destaca como local para lavar objetos e despejo de dejetos. Essa representação é demonstrativa da ação nociva que afeta a qualidade da água. A contribuição para essa 
poluição por parte da comunidade é grande, conforme o discurso: "o rio é local para onde a descarga dos banheiros deve ir".

As atividades como lavar roupa, lavar louça, dar descarga, atividades de lazer dentre outras afetam outro parâmetro de qualidade da água, a turbidez. De acordo com a Agência de Proteção Ambiental dos Estados Unidos (USEPA, 1997) o uso social da água (Tabela 4), que envolve atividades diárias, contribui na alteração dos parâmetros de turbidez da água.

Tabela 4. Fontes, poluentes e discursos associados.

\begin{tabular}{|c|c|c|}
\hline Fonte & Parâmetros poluentes associados & Trechos dos discursos associados \\
\hline Terras agrícolas & $\begin{array}{l}\text { Turbidez, fósforo, nitratos, } \\
\text { temperatura. }\end{array}$ & $\begin{array}{c}\text { “A água pra mim é uma fonte que ajuda na produção, planta } \\
\text { muita coisa e irriga estas plantas, Para tudo o rio é } \\
\text { importante, tem importância fundamental para irrigação". }\end{array}$ \\
\hline Pastagens & $\begin{array}{l}\text { Bactérias fecais, turbidez, fósforo, } \\
\text { nitratos e nitrogênio amoniacal. }\end{array}$ & $\begin{array}{l}\text { "Lá cria gado e sem água não teria jeito. A água vai } \\
\text { estimular pecuária, sem água os animais não produzem, a } \\
\text { água tem muito valor e beneficia a criação”. }\end{array}$ \\
\hline $\begin{array}{l}\text { Uso social da água para } \\
\text { atividades diárias }\end{array}$ & Bactérias fecais, turbidez, fósforo. & $\begin{array}{c}\text { "Eu preciso dos rios para pegar água para gente usa no dia } \\
\text { a dia, a gente precisa de água pra nós lava roupa, pra nós } \\
\text { faze a comida, lava as vasilhas, carregam os dejetos dessas } \\
\text { pessoas, aquilo que vem do banheiro joga no rio”. }\end{array}$ \\
\hline
\end{tabular}

Fonte: Baseado em USEPA 1997a, 1997b.

Trechos do discurso dessa respectiva RS apresentam outros impactos específicos que também devem ser analisados: "se tiver muito calor a gente pode ir lá nadar naquele córrego, a gente pode pescar se lá tiver peixe e ajuda a dar um local pra gente poder ir passear, ir lá conferir como que ta o córrego, é lazer, é bonito de se ver". Cole (2004, p. 118) mostrou que os impactos do lazer e recreação em geral em rios e ambientes naturais podem degradá-lo rapidamente, sendo estes danos estáveis durante longos períodos, e o tempo de recuperação ambiental são tipicamente maiores do que as taxas de degradação. Esses fatores afetam o ambiente no sentido da diminuição da importância ecológica do local. Estes impactos incluem a quantidade, tipo, tempo e distribuição espacial da utilização, o comportamento do usuário, resistência e resiliência da configuração do ambiente.

Quando somadas as porcentagens dos entrevistados que tem ICs de que os rios e córregos são importantes para a produção e de que os rios e córregos são importantes no dia-a-dia das pessoas, tem-se $64,0 \%$ dos entrevistados com essas respectivas ICs trazendo consigo RS com maior potencial de impactar negativamente a qualidade dos rios e córregos que cortam suas comunidades.

\section{Rios e córregos são importantes na dinâmica ambiental}

Do total de respostas, cinco, foram utilizadas para construção do DSC da IC de que os rios e córregos são importantes na dinâmica ambiental. Ao utilizar as IC extraídas das ECH das respostas dos membros da comunidade, foi possível construir um discurso que demonstrou preocupação com questões ambientais e problemas locais relacionados a não-conservação dos recursos ambientais: " $E u$ acho que é importante porque faz parte do meio ambiente, irriga as bacias, dá um refresco para quem mora perto dele, refresca um pouco a temperatura, melhora a questão de ar, atrai animal e é fundamental para o equilibrio do ecossistema do ambiente".

A pergunta 1 teve 10,0\% de ICs que consideraram que os rios e córregos são importantes para a dinâmica ambiental. Essa parcela de entrevistados mostrou-se mais preocupada com questões ambientais. Para Rouquette (1997) o envolvimento pessoal varia em relação a três dimensões: exposição pessoal a um problema, o valor colocado sobre essa questão e a representação e capacidade de agir em direção a ela. Assim, na medida em que o ambiente é o grande foco de discussão, e seguindo o âmbito da presente teoria das RS, quanto mais um indivíduo valoriza um determinado assunto, mais ele se sente pessoalmente exposto a ele e quanto mais ele se sente exposto, mais ele é capaz de agir em direção a ele. Dessa maneira o indivíduo e o grupo social ao qual pertence tem maior 
propensão a adotar ações que não comprometam o ambiente, levando em conta o valor que atribui ao tema comparativamente com outras RS e seus respectivos discursos associados. Quando um indivíduo menciona em sua resposta questões de ordem ambiental que corroboram a importância da água, compreende-se, pela teoria das RS, que suas práticas são mais sustentáveis.

Moser (1984) diz que a adoção de comportamentos pró-ambientais não parece depender da percepção e do objetivo do problema, em vez disso, parece ser ligada à representação que o indivíduo tem de tal elemento do meio ambiente. Fransson e Garling (1999) em seus estudos mostram que interesse ambiental expresso em representações é considerado como sendo uma atitude positiva em relação ao ambiente, onde desempenha um significativo papel na adoção de uma nova conduta próambiente.

De acordo com o DSC que indicou como IC que os rios e córregos são importantes na dinâmica ambiental, pode-se afirmar que, em comparação com outros grupos, estes manifestam comportamento mais adequado na sua relação com os RH, o que demonstra a eficácia desse modo de avaliação.

\section{Água é vida}

Do total de respostas analisadas, 13 foram selecionadas para construção do seguinte DSC de que água é vida: "É um bem comum essencial a vida, porque se num tiver água você não consegue sobreviver, manter sua condição de vida e sobrevivência das pessoas e animais. Sem água não existe sobrevivência, ela é fonte de vida, vamos dizer assim, água é vida. O rio ele é fonte de riqueza e importante para manter a vida dos seres vivos e a vegetação. Sem água num vive, né? Como vai viver sem água? ". ${ }^{3}$ Outros três entrevistados não responderam ao questionamento realizado para a pergunta 1.

A pergunta 1 teve $26,0 \%$ de ICs que consideraram que os rios e córregos são importantes porque representa vida. Dentro do senso comum que permeia essa IC é importante identificar, descrever e analisar os significados estruturados e a comunicação do conhecimento do senso comum sobre questões socialmente significativas como é o caso da água (LIU, 2004).

Estudando as RS da água Polli et al. (2009) afirma que esse núcleo central de que água é vida, evidencia a compreensão da água como um elemento essencial à vida, que é ligado à saúde e precisa ser preservado. A necessidade da sustentabilidade é suscitada quando se pensa na água, pois ela é considerada como necessária à sobrevivência.

Considerando que o grupo estudado recebe informações sobre a água de modo semelhante ao da população em geral, podemos ter em conta que a expressão "água é vida" vem sendo dita pela mídia, pelos ambientalistas, pela educação ambiental e pelo próprio sistema educacional há muito tempo. Tal representação demonstra aos gestores o anseio da população de ver equacionado o frágil equilíbrio entre as exigências econômicas e a preservação ambiental. Observa-se que a manutenção da sobrevivência implica uma reconsideração notável nas práticas em favor dos RH (FUNASA, 2006).

Dessa forma, o estudo da RS é de fundamental importância para que possamos compreender melhor as inter-relações entre o homem e o ambiente, suas expectativas, anseios, satisfações e insatisfações, julgamentos e condutas em relação a água. A Tabela 5 apresenta o resumo do quantitativo das diferentes RS trabalhadas.

\footnotetext{
${ }^{3}$ Sujeitos: (JOV007; JOV012; TEC001; TEC002; TEC003; TEC004; ESC001; ESC002; ESC004; ESC007; PROD004; PROD006; PROD008).
} 
Tabela 5. Quantitativo das diferentes RS onde a cor vermelha apresenta as RSMAI - representações sociais impactantes e RSMEI - representações sócias menos impactantes.

\begin{tabular}{|c|c|c|c|}
\hline \multicolumn{4}{|c|}{ Rios e córregos (\%) } \\
\hline Produção & 30 & RS mais Impactantes (RSMAI) & 64 \\
\hline Dia-Dia & 34 & RS Menos Impactantes (RSMEI) & 36 \\
\hline Dinâmica ambiental & 10 & 100 & 100 \\
\hline Água é vida & 26 & & \\
\hline Total & \multicolumn{3}{|c|}{} \\
\hline
\end{tabular}

Fonte: Elaborada pelo autor

Apesar do quantitativo das RSMAI serem maiores em termos relativos, isso não significa que essa porcentagem é determinante na relação de impactar ou não os recursos hídricos da região. Junto com outras ferramentas de análises, a teoria das RS deve dar um direcionamento dos pensamentos e tentar analisar as práticas dos indivíduos em direção ao ambiente.

Diante disso, outros fatores colaboram para a análise da degradação ambiental local sendo importante analisa-las. Dessa forma deve-se levar em conta as práticas dos indivíduos com o meio ambiente e recursos hídricos considerando seus pensamentos e outras influências para a análise de suas práticas ambientais. Irwin e Bockstael (2004) afirmam que as práticas sociais relacionadas com o ambiente são fenômenos de nível regional impulsionado por escolhas individuais ou coletivas que são influenciadas por uma miríade de fatores, incluindo características da terra, infraestruturas, políticas e características individuais. Essas intervenções do indivíduo no ambiente vêm de um resultado acumulativo de ações individuais. Uma compreensão das práticas ambientais de uma localidade requer um entendimento do indivíduo, suas tomadas de decisão e como essas decisões " acrescentam " ao longo do tempo no espaço e no ambiente.

Uma característica central de conflitos ambientais é a complexidade do sistema ecológico, que é a base natural dos conflitos. Irwin e Bockstael (2004) afirmam que mesmo se a pessoa tiver um alto grau de instrução acadêmica-cientifica, permanecerá uma incerteza e ignorância substancial quanto às práticas ambientais. Questões de impacto, causalidade de escalas espaciais e temporais que muitas vezes dão origem a diferentes hipóteses plausíveis, sem indicação clara sobre suas respectivas probabilidades. O processo condizente à resolução de conflitos ambientais deve levar em consideração que o conhecimento cientifico muitas vezes considera exceções e situações incomuns, o que muitas vezes conduz o trabalho a resultados que não podem ser generalizados e devem ser relativizados, sendo esse resultado um indicativo de um caminho a seguir rumo ao entendimento amplo e profundo de determinado assunto.

$\mathrm{Na}$ busca de elementos e fatores que levam ao entendimento amplo de determinado assunto temos o dever de levantar a perspectiva de outras informações que contribuem para a análise das RS e das práticas individuais para com os recursos hídricos. A questão socioeconômica por exemplo, é um indicativo sobre as práticas ambientais voltadas para os recursos hídricos que conjuntamente com a análise das RS fornecem ferramentas importantes de análise de uma comunidade. Broussard et al. (2008) analisam a questão socioeconômica de comunidades relacionando-a com as práticas ambientais; afirmam que as comunidades com maior status socioeconômico são mais propensas a impor controles do uso da terra para proteger valores ambientais da localidade.

Coomes et al. (2000) em um de seus estudos que relacionam status socioeconômico versus práticas ambientais, demonstram que o fato de o indivíduo ter melhores condições financeiras pode ser bom ou ruim para o meio ambiente. Eles demostram isso através da análise da dinâmica da biodiversidade de comunidades amazônicas. Os autores afirmam que o aumento de renda pode variar mesmo dentro de uma comunidade estudada e essa mudança do status socioeconômico pode trazer resultados positivos para a conservação ambiental como no caso de algumas famílias que diminuíram sua extração florestal e investiram em jardins agroflorestais. De outro lado, o aumento do poder 
financeiro levou indivíduos que desmatavam de forma limitada através de machados, a comprar motosserras e desmatar a floresta ainda mais rápido.

Broussard et al. (2008) afirmam que já existe um certo consenso afirmando que a questão socioeconômica da população também é um indicativo se o indivíduo tende a conservar ou não um determinado local. Segundo eles a riqueza explica em grande parte as atitudes do indivíduo para com o ambiente. Van liere e Dunlap (1980) desenvolveram também um estudo para verificar a influência de aspectos socioeconômicos no comportamento ambiental. Revisaram 21 estudos empíricos que avaliam o grau de fatores socioeconômicos e tentam explicar as diferenças na preocupação ambiental concluindo que os rendimentos do indivíduo são apenas um explicativo limitado em relação ao comprometimento com a conservação ambiental. Apesar do aspecto controverso dessa teoria, ela ainda parece valiosa junto a outras ferramentas, como as RS, para se analisar a perspectiva de conservação de uma comunidade (PRATT e ROGERS, 1986; SOLECKI et al., 2004).

Tole (2002) em um estudo realizado na Jamaica também levantou alguns motivos para o desmatamento de áreas naturais, como o uso de lenha, densidade populacional e necessidade de subsistência. $\mathrm{O}$ autor também concluiu que as variáveis socioeconômicas indicam um importante papel no desmatamento na ilha.

Berke e Beatley (1995) acrescentam ainda que problemas de danos ambientais incluem: a falta de financiamento para o monitoramento e aplicação adequados das atividades em torno do parque, a má delimitação das fronteiras das áreas protegidas e opções insuficientes para os moradores trocarem suas atividades destrutivas por não destrutivas ao ambiente.

Nessa perspectiva, a compreensão da dinâmica evolutiva da paisagem e de conservação dos recursos hídricos pode ser chave no processo de gestão ambiental. Segundo Wilson e Forman (1995), o entendimento do processo humano de alteração do padrão natural pode ser o ponto de entrada na alteração do comportamento e na implementação de novas políticas e projetos ecológicos. Alguns grupos de ecologistas criticaram duramente esses projetos ecológicos, alegando que não convidam verdadeiramente a participação local na gestão ambiental, mas sim constituem formas coercitivas de prática de conservação, que se assemelham a "esforços coloniais malfadados para converter agricultores itinerantes em agricultores progressistas ". Por esse ponto de vista, para ter sucesso, os projetos precisam delegar verdadeiramente autoridade para comunidades (TREVES et al. 2005).

Desvendar o ser humano parece muitas vezes ser uma tarefa dificil, pois as açoes dos individuos para com o ambiente não pode ser modelado. Porem informaçoes relevantes sobre determinada população são fundamentais para tecer analises e hipoteses, caminhando no sentindo da sustentabilidade ambiental buscando melhor entender o ser humano, que tem que ser o foco de projetos de conservação ambiental. Tole (2002) afirma que há necessidade de se abordar a dimensão humana da conservação da biodiversidade como um primeiro passo no desenvolvimento de um plano de gestão para o uso sustentável dos recursos naturais pelas comunidades locais e em torno da região.

\section{CONSIDERAÇÕES FINAIS}

Não se pode afirmar aqui, neste trabalho, que o indivíduo ou grupo social que possui determinada RS vai agir da maneira como indica seu discurso. O que se tenta demonstrar é que, dependendo da RS do indivíduo, existe uma propensão maior ou menor dele adotar determinada postura em relação a um dado objeto. Através desta ferramenta, pode-se visualizar a fragilidade de algumas regiões, avaliar suas possibilidades e propor reflexões rumo a diretrizes eficazes. Desta forma este trabalho apresentou que a teoria das RS junto com a metodologia do DSC fornece embasamento teórico sólido ao relacionar os discursos e as respectivas RS com práticas ambientais, apresentando dados de qualidade de água e de uso e cobertura do solo

O estudo do uso e cobertura do solo validou o pensamento da comunidade através das RS e como as RS se manifestam no ambiente. Esse estudo caracterizou e tipificou o ambiente estudado, considerando os efeitos decorrentes do manejo inadequado do solo. Assim deu-se mais um passo 
científico em relação ao desafio na abordagem de conservação que estamos enfrentando no caminho para a sustentabilidade ambiental, juntamente com a questão social e sistemas naturais de pesquisa.

O trabalho evidenciou que as análises de água são de fundamental importância no relacionamento das RS com seus impactos nos RH das comunidades levando-se em consideração que a qualidade da água é um reflexo do uso e manejo do solo da $\mathrm{BH}$ em questão. O trabalho evidenciou que é necessário que a poluição dos RH no meio rural seja monitorada onde as análises da qualidade da água de uma determinada bacia é um apoio importante nesse contexto.

A pesquisa de campo, necessária ao levantamento dos dados, mostrou que a aproximação entre o saber acadêmico e as realidades regionais, constitui-se fonte inesgotável de conhecimento para ambas as partes. Os saberes, igualmente importantes, tem se mostrado vitais para a experimentação de práticas sustentáveis que permitirão que os recursos hídricos sigam seu curso, utilizados de maneira consciente. Assim deu-se mais um passo científico em relação ao desafio na abordagem de conservação que estamos enfrentando no caminho para a sustentabilidade ambiental, chamando-nos a responsabilidade de atuarmos como monitores permanentes, remunerados ou não, a serviço de nossa própria sobrevivência.

\section{AGRADECIMENTOS}

Ao apoio técnico, logístico e financeiro agradeço a EMBRAPA Gado de Leite, CAPES, CNPQ e FAPEMIG.

\section{REFERENCIAS}

ABRIC, J.C. A structural approach to social representations. In K. Deaux, \& G. Philogene (eds.), Representations of the social: Bridging theoretical traditions, Malden: Blackwell Publishing, pp. 42-47, 2001a.

ABRIC, J.C. Pratiques sociales, representations sociales S. In J.C. Abric (eds.), Pratiques sociales et representations Presses Universitaires de France, Paris, pp. 217-238. 2001c.

ABRIC, J.C. Social representations: Theoretical aspects. In J.C. Abric (eds.), Pratiques sociales ET representations, Presses Universitaires de France, Paris, pp. 11-35. 2001b.

BECKER, B. K.; MIRANDA, M. A Geografia Política do Desenvolvimento Sustentável. Porto Alegre: EdUFRJ, 1997. p. 13-44.

BERKE, P. R.; BEATLEY, T. Sustaining Jamaica's forests: The protected areas resource conservation project. Environmental Management, 19, n. 4,. pp. 527-545. 1995.

BOYNE R, Arthur JR. The response of selenium-deficient mice to Candida albicans infection. $J$ Nutr. May;116(5):816-822. 1986

BRASIL, Ministério do Meio Ambiente, Conselho Nacional do Meio Ambiente - CONAMA Resolução $\mathrm{n}^{\circ}$ 357 de 17 de março de 2005. Dispõe sobre a classificação dos corpos de água e diretrizes ambientais para o seu enquadramento, bem como estabelece as condições e padrões de lançamento de efluentes, e dá outras providências. DOU, Brasília, Brasil. 2005.

BROUSSARD, S. R.; WASHINGTON-OTTOMBRE, C.; MILLER, B. K. Attitudes toward policies to protect open space: A comparative study of government planning officials and the general public. Landscape and Urban Planning, 86, n. 1,. pp. 14-24. 2008.

COLE, D.N. Environmental impacts of outdoor recreation in wildlands. In: Manfredo MJ, Vaske JJ, Bruyere BL, Field DR, Brown PJ (eds.), Society and natural resources: a summary of knowledge. Modern Litho, Jefferson, MO, pp. 107-126. 2004.

COOMES, O. T.; GRIMARD, F.; BURT, G. J. Tropical forests and shifting cultivation: secondary forest fallow dynamics among traditional farmers of the Peruvian Amazon. Ecological Economics, 32, n. 1,pp. 109124. 2000 
FÈLONNEAU, M. Les représentations sociales dans le champ de l'environnement. In: MOSER, G.; WEISS, K. (Org.) Espaces de vie: aspects de la relation homme-environnement. Paris: Armand Colin,. p. 145-176. 2003.

FLAMENT, C. Practices and social representations. In J.L. Beauvois, R.V. Joule, \& J.-M. Monteil (Eds.), Perspectives cognitives et conduites sociales. Theories implicates et conflits cognitifs, Cousset, DelVal, pp. 143-150. 1987.

FRANSSON, N. e GARLING, T. Environmental concern: Conceptual definitions, measurement methods, and research findings. Journal of Environmental Psychology 19: 369-382. 1999.

FUNASA. Relatório de Pesquisa: Representações e praticas sociais ligadas à água. Fundação Nacional da Saúde. 2006.

GRAY, C. L., BILSBORROW, R. E., BREMNER, J. L., LU, F. Indigenous Land use in the Ecuadorian Amazon: A Crosscultural and Multilevel Analysis. Human Ecology 36(1): 97-109. 2008.

GUILLOU, E., M., MOSER G. Commitment of farmers to environmental protection: From social pressure to environmental conscience. Journal of Environmental Psychology 26 (3): 227-235. 2006.

GUIMARÃES, R. Desenvolvimento sustentável: da retórica à formulação de Políticas Públicas. In: BECKER, B. K.; MIRANDA, M. A Geografia Política do Desenvolvimento Sustentável. Porto Alegre: EdUFRJ, 1997. p. 13-44.

GUIMELLI, C. Chasse et nature en Languedoc. Etude de la dynamique d'une representation sociale chez des chasseurs languedociens [Hunting and nature in Languedoc. Study of the dynamics of a social representation among hunters from Languedoc]. L’Harmattan, Paris. 1998.

HERMES, L. C., SILVA, S. A. Avaliação da qualidade das águas: manual prático. Embrapa Informações Tecnológicas. 2004.

HOGAN, D. J. Crescimento populacional e desenvolvimento sustentável. Lua Nova, 31, pp. 57-77. 1993.

IRWIN, E. G.; BOCKSTAEL, N. E. Land use externalities, open space preservation, and urban sprawl. Regional science and urban economics, 34, n. 6, pp. 705-725. 2004.

JACOBI, P. E. A.. . V. 1. N. 3. P. 2. Educação ambiental, cidadania e sustentabilidade. Cadernos de pesquisa, 118, n. 3, pp.189-205. 2003.

JACOBI, P.; CASCINO, F.; OLIVEIRA, J. F. D. Educação, meio ambiente e cidadania: reflexões e experiências. In: AMBIENTE., S. D. M. Educação, meio ambiente e cidadania: reflexões e experiências. São Paulo: [s.n.], 1998.

JODELET, D. Representations sociales: Un domaine en expansion [Social representations: An expanding domain]. In D. Jodelet (Ed.), Les representations socials, Presses Universitaires de France, Paris, pp. 47-78. 1997.

LAMBIN, E., GEIST, H. Land-Use and Land-Cover Change: Local Processes and Global Impacts.Springer, Washington, DC. 2006.

LEFEVRE, F., LEFEVRE, A.M.C. O discurso do sujeito coletivo: um novo enfoque em pesquisa qualitativa. Ed. Educs ,Caxias do Sul, Brasil. 2003.

LEFEVRE, F., MARQUES, M. C. C.; LEFEVRE, A. M. C. Representação social da Vigilância Sanitária pela população do município de Águas de Lindóia: análise da percepção de alguns riscos relevantes. Revisa 1 (1): 22-30. 2005 .

LILLESAND, T.M., KIEFER, R.W. Remote Sensing and Photo Interpretation. John Wiley \& Sons, New York. 1994.

LIU J., DIETZ, T., STEPHEN, R. ALBERTI, M., FOLKE, C. Complexity of coupled human and natural systems. Science 317 (5844): 1513-1516. 2007.

LIU, J.; OUYANG, Z.; TAYLOR, W. W.; GROOP, R.; ZHANG, H. A framework for evaluating the effects of human factors ob wildlife habitat: the case of giant pandas. Biological Conservation, v.13 n. 6, p.1360$1370,1999$.

LIU, L. Sensitising concept, themata and shareness: A dialogical perspective of social representations. Journal for the Theory of Social Behaviour 34 (3): 249-264. 2004. 
MINAYO, M. C. S. O desafio do Conhecimento: pesquisa qualitativa em saúde, Ed. Hucitec, São Paulo, Brasil. 2007.

MOSCOVICI, S. Notes towards a description of social representations. European Journal of Social Psychology 18 (3): 211-250. 1988.

MOSCOVICI, S. The history and actuality of social representations. In U. Flick (Eds.), The psychology of the social Cambridge University Press, New York, pp. 209-247. 1998.

MOSER, G. Water quality perception, a dynamic evaluation. Journal of Environmental Psychology 4: 201210. 1984.

OLDEKOP J. A., BEBBINGTON, A. J., TRUELOVE, N. K., HOLMES, G., VILLAMARÍN S., RICHARD F. P. Environmental Impacts and Scarcity Perception Influence Local Institutions in Indigenous Amazonian Kichwa Communities. Human Ecology 40:101-115. 2012.

PICHÓN, F. J. Settler Agriculture and the Dynamics of Resource Allocation in Frontier Environments. Human Ecology 24(3): 341-371. 1996.

POLLI, G. M., KUHNEN A., AZEVEDO, E. G., FANTIN, J. da S. R. F. G.Representações sociais da água em Santa Catarina. Psicologia em Estudo 14 (3): 529-536. 2009.

PRATT, S. R.; ROGERS, D. L. Correlates of the adoption of land use controls. Rural Sociology, 51, n. 3, pp. 354. 1986.

ROUQUETTE, M.L. La chasse a' l'immigre': Violence, me'moire et repre'sentations [Immigrant hunting: Violence, memory and representations]. Pierre Mardaga, Sprimont. 1997.

SILVA, T. C., MEDEIROS, P. M., ARAUJO, T. A. S., ALBUQUERQUE, U. P. Northeastern Brazilian students' representations of Atlantic Forest fragments. Environment, Development and Sustainability 12 (2): 195-211. 2010.

SOLECKI, W. D.; MASON, R. J.; MARTIN, S. The Geography of Support for Open-Space Initiatives: A Case Study of New Jersey's 1998 Ballot Measure. Social Science Quarterly, 85, n. 3, pp. 624-639. 2004.

STOREY, C.; OLIVEIRA, H. T. Social representations and environmental education with a women's group in Manaus, Amazonas-Brazil. Environmental Conservation, Manaus, v.31 n.4 p. 299-308, 2004.

TOLE, L. Habitat loss and anthropogenic disturbance in Jamaica's Hellshire Hills area. Biodiversity and Conservation, pp. 575-598. 2002.

TREVES, L. N.; HOLLAND, M. B.; BRANDON, K. The role of protected areas in conserving biodiversity and sustaining local livelihoods. Annu. Rev. Environ. Resour, pp. 21-52. 2005.

USEPA. BASINS Training Course, December 8 12, 1997. U.S. Environmental Protection Agency, Office of Water, Washington, DC. 1997b.

USEPA. EPA's Techniques for Tracking, Evaluating, and Reporting the Implementation of Nonpoint Source Control Measures-Agriculture. EPA 841-B-97-010. U.S. Environmental Protection Agency, Office of Water, Washington, DC. 1997a.

VAN LIERE, K. D.; DUNLAP, R. E. The social bases of environmental concern: A review of hypotheses, explanations and empirical evidence. Public opinion quarterly, 44, n. 2, pp. 181-197. 1980.

WILSON, E. O.; FORMAN, R. T. T. "Land mosaics: the ecology of landscapes and regions. Cambridge University. Cambridge, pp. 656. 1995. 